\title{
Hypothyroidism and Nephrotic Syndrome: Why, When and How to Treat
}

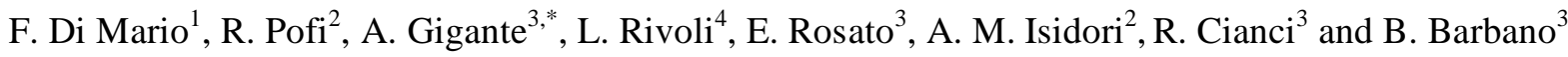 \\ ${ }^{I}$ Department of Internal Medicine and Medical Specialties, Sapienza University of Rome, Rome, Italy; ${ }^{2}$ Department of \\ Experimental Medicine, Sapienza University of Rome, Rome, Italy; ${ }^{3}$ Department of Clinical Medicine, Sapienza Univer- \\ sity of Rome, Rome, Italy; ${ }^{4}$ Nephrology and Dialysis Unit, Magna Graecia University, Catanzaro, Italy
}

\begin{abstract}
Hypothyroidism, characterised by low/normal free thyroxine $\left(\mathrm{FT}_{4}\right)$ and free tri-iodothyronine $\left(\mathrm{FT}_{3}\right)$ with elevated thyroid-stimulating hormone (TSH), is a well-known complication of nephrotic syndrome (NS). This is a common feature of primary and secondary glomerular diseases and comprises loss of protein in the urine and increased urinary excretion of thyroid hormones and thyroxine-binding globulin. With a normal thyroid reserve, this scenario is associated with the development of subclinical hypothyroidism, with a slight increase in TSH and normal free fractions. However, with a low thyroid reserve the transition toward overt hypothyroidism is almost inevitable, affecting morbidity and mortality. As T4 replacement is a cheap and well-established treatment to achieve a stable hormone status in different types of thyroid deficiency, it is essential to recognise and appropriately treat this condition. In this article we summarise the evidence on this nephro-endocrine disorder in humans and focus on diagnostic and therapeutic strategies.
\end{abstract}

A R T I C L E H IS T O R Y

Received: June 30, 2016

Accepted: January 31, 2017

DOI:

$10.2174 / 15701611159991702071147$

06

Keywords: Nephrotic syndrome, hypothyroidism, glomerulonephritis, thyroid hormones, replacement.

\section{INTRODUCTION}

Despite the considerable available data, the exact prevalence of hypothyroidism and subclinical hypothyroidism in adult patients with nephrotic proteinuria is still unclear [1]. Surprisingly, the 2012 clinical practice guidelines for glomerulonephritis do not mention hypothyroidism as a complication of glomerular disease [2], leading to a risk of its serious underdiagnosis. However, the latest American guidelines for the treatment of hypothyroidism underline the role of severe urinary protein loss in increasing replacement therapy requirements [3]. For these reasons, this review focuses on the most recent evidence and information on this topic.

\section{PATHOPHYSIOLOGY}

The hypothalamic-pituitary-thyroid axis is a complex endocrine system which controls the production of thyroid hormones. The paraventricular nucleus of the hypothalamus secretes thyrotropin-releasing hormone, which in turn leads to pituitary secretion of thyroid-stimulating hormone (TSH). TSH binds to thyroid receptors and stimulates the biosynthesis and secretion of thyroxine $\left(\mathrm{T}_{4}\right)$ and tri-iodothyronine $\left(\mathrm{T}_{3}\right)$ into the plasma [4]. The steps involved are: (i) transport of iodine into the thyroid gland; (ii) iodination of thyroglobulin tyrosyl residues, resulting in synthesis of either monoiodinated tyrosine (MIT) or di-iodinated tyrosine (DIT),

\footnotetext{
*Address correspondence to this author at the Department of Clinical Medicine, Sapienza, University of Rome, Viale dell'Università, 37, 00185 Rome, Italy; Tel/Fax: +39 06 49972074; E-mail: antonietta_gigante@yahoo.it
}

incorporated into thyroglobulin; (iii) coupling of iodotyrosines to form the hormonally active iodothyronines: two DITs lead to the formation of $\mathrm{T}_{4}$, while one DIT plus one MIT lead to $\mathrm{T}_{3}$ synthesis.

The hormones thus formed are held in thyroglobulin, the major component of intrafollicular colloid. The active thyroid hormones free $\mathrm{T}_{3}\left(\mathrm{FT}_{3}\right)$ and free $\mathrm{T}_{4}\left(\mathrm{FT}_{4}\right)$ are released through the hydrolysis of thyroglobulin by a thyroid protease and peptidases [5]. About $85 \mu \mathrm{g}$ of $\mathrm{T}_{4}$ are secreted by the thyroid gland every day, while only $20 \%$ of the $33 \mu \mathrm{g}$ of normally circulating $\mathrm{T}_{3}$ derives from direct thyroid release. The rest $(80 \%)$ is produced by a peripheral $\mathrm{T}_{4}$ deiodination reaction involving a specific enzyme which removes one iodine from the outer ring of $\mathrm{T}_{4}$ [6]. Thyroid hormones are linked with the plasma binding proteins thyroxine-binding globulin (TBG), transthyretin and human serum albumin during transport; these account, respectively, for 74, 11 and $15 \%$ of all $\mathrm{T}_{4}$ binding. The high affinities of the binding proteins result in a slow clearance and prolonged half-life of thyroid hormones in the circulation [7].

Upon release to the target tissues through different carriers, thyroid hormones undergo cytosolic enzymatic reactions, involving $\mathrm{T}_{4}$ deiodination by iodothyronine deiodinases (types 1, 2 and 3) [8]. The selective removal of an iodine atom from the phenolic (outer) ring produces the biologically active hormone $\mathrm{T}_{3}$, whereas its removal from the tyrosyl (inner) ring generates the inactive metabolite reverse $\mathrm{T}_{3}$. These reactions play a crucial role in the homeostasis of thyroid hormones [4]. The final step of this cascade is the 
interaction between active hormones and their nuclear thyroid hormone receptors, which modulates gene transcription in response to hormones [9].

While hypothyroidism is defined as high serum TSH with concomitant low levels of $\mathrm{FT}_{3}$ and $\mathrm{FT}_{4}$, subclinical hypothyroidism involves elevated TSH despite normal serum levels of $\mathrm{FT}_{3}$ and $\mathrm{FT}_{4}$ [10]. The American Association of Clinical Endocrinologists/American Thyroid Association recommends treating the latter condition only in symptomatic patients positive for thyroid antibodies or with cardiovascular risk factors [3]. There are no clinical outcome data supporting levothyroxine $\left(\mathrm{LT}_{4}\right)$ treatment in patients with serum TSH levels between 2.5 and $4.5 \mathrm{mIU} / \mathrm{L}$ [3]. It is recommended that all patients with subclinical hypothyroidism and a TSH $>10 \mathrm{mIU} / \mathrm{L}$ be treated with $\mathrm{LT}_{4}$, as they have higher all-cause mortality [11]. Hypothyroidism and moderate subclinical hypothyroidism are associated with increased all-cause mortality independent of coronary heart disease [11] and with increased risk of heart failure [12].

According to most recent guidelines, NS in adults is defined as a complex alteration of the glomerular filtration barrier which results in proteinuria $>3.5 \mathrm{~g} / 24 \mathrm{~h}$, hypoalbuminaemia $(<3 \mathrm{~g} / \mathrm{dL})$, peripheral oedema and often hyperlipidaemia. Heavy proteinuria $(>3.5 \mathrm{~g} / 24 \mathrm{~h})$ without the clinical features of NS is commonly referred to as isolated nephrotic proteinuria [2]. This specific presentation of kidney disease may occur in a wide variety of primary and systemic diseases and its incidence is estimated to be three new cases per 100000 each year [13]. In adults, the main causes seem to be primary glomerulonephritis (in particular membranous nephropathy and focal segmental glomerulosclerosis), while approximately $30 \%$ of cases are due to a systemic disease such as diabetes mellitus, systemic lupus erythematosus or amyloidosis [14-17]. Complications in NS may be part of the disease itself or develop as a consequence of its treatment [18]. The loss of proteins in the urine changes their plasma concentrations, causing secondary insufficiency and impairment of metabolic functions [19].

Abnormal thyroid function is a not uncommon complication of nephrotic diseases. Its pathophysiology was first investigated in 1926, when Albert A. Epstein postulated a common aetiology for hypothyroidism and nephrotic state [20]. It was later clarified that $\mathrm{LT}_{4}$ is ineffective in the treatment of proteinuric diseases and that hypercholesterolaemia in nephrosis is not only related to hypothyroidism, but above all to the urinary loss of lipoprotein binding proteins [21, 22]. In fact, although the exact cause appears to be complex, dysthyroidism in NS has been explained by the loss of hormone binding proteins occurring in this setting [23]. The large fraction of thyroid hormones bound to plasma proteins pass the glomerular filtration barrier and are lost in urine, as they are only partly reabsorbed in the proximal tubule by megalin and cubilin complexes [24]. The progressive tubular defect typically seen in chronic proteinuric diseases may then exacerbate the pre-existing decline of circulating thyroid hormone.

Small observational studies of the renal metabolism of $\mathrm{FT}_{3}$ and $\mathrm{FT}_{4}$ conducted in healthy subjects have demonstrated that $\mathrm{FT}_{4}$ is usually mostly reabsorbed by the tubules, while $\mathrm{FT}_{3}$ is just secreted [25, 26]. A tubular dysfunction may therefore affect $\mathrm{FT}_{3}$ and $\mathrm{FT}_{4}$ metabolism, worsening the primary glomerular insufficiency. Although evidence of urine excretion of $\mathrm{T}_{4}, \mathrm{~T}_{3}$ and TBG in NS is limited, most studies have confirmed the high excretion of $\mathrm{T}_{4}$ and $\mathrm{T}_{3}$ during nephrosis [27]. Furthermore, there was a positive correlation between $24 \mathrm{~h}$ proteinuria and urinary concentration of $\mathrm{T}_{4}, \mathrm{~T}_{3}$ and TBG in patients with NS, while serum TSH was negatively correlated with albumin [28]. In other words, the increase in TSH is correlated with the degree of proteinuria, and is thus a possible predictor of worsening kidney failure [1]. Furthermore, in some clinical trials hypothyroidism was associated with oedema onset and there was a remission of protein loss upon relief of the hypothyroidism [29]. However, as recent literature confirms, most patients with NS have subclinical hypothyroidism, with normal $\mathrm{FT}_{3}$ and $\mathrm{FT}_{4}$ levels and elevated TSH compared with basal values [30]. This indicates that the thyroid is normally able to compensate for the urinary loss of hormones and patients remain euthyroid. However, if a primary glandular disease coexists, overt hypothyroidism can develop, leading to an increase in exogenous levothyroxine requirements [31].

In any case, the hormonal thyroid profile in nephrotic states is highly variable and hypothyroidism is known to have different degrees of severity [32]. In consequence, dysthyroidism in nephrotic kidney diseases is likely to have a more complicated pathophysiology. In addition, TSH is a low molecular weight protein $(28.5 \mathrm{kDa})$, which can be lost in urine in patients with glomerular disease. Increased urinary excretion of TSH has been reported in some smallcaseload studies, suggesting another possible explanation for non-constant onset of hypothyroidism among these patients [33]. Obviously, the difference in proteinuria selectivity may itself further confuse the hormone profiles, producing different degrees of hypothyroidism in patients with different glomerulopathies [34]. Furthermore, it has already been shown that a lower $\mathrm{T}_{3}$ level correlates with a higher urinary amount of $\mathrm{T}_{4}$. This might be explained by a decreased peripheral conversion of $T_{4}$ to $T_{3}$, suggesting a possible reason for the various presentations [32].

The considerable impact of hypothyroidism in nephrotic diseases could also be related to the concomitant presence of any acute and/or chronic renal impairment. Elevated serum creatinine and reduced glomerular filtration rate have been associated with subclinical hypothyroidism [35]. The pathophysiological mechanisms underlying this association were thought to be the decline of renal plasma flow, promoted by the imbalance between stroke volume and peripheral resistance [36], hyperlipidaemia [37] and the effects of paracrine and endocrine mediators such as insulin-like growth factor type 1 and vascular endothelial growth factor [30]. Furthermore, an interconnection between thyroid dysfunction and renal impairment has been observed in several case series where complete remission of hypothyroidism was achieved only on reaching end stage renal disease [38, 39].

Another point to be clarified with regard to NS and dysthyroidism is the key role played by altered iodine metabolism in proteinuric diseases [40]. Briefly, nonautoimmune hypothyroidism in NS cannot be explained by the substantial urinary excretion of $\mathrm{T}_{4}, \mathrm{~T}_{3}$ and TBG alone. An increased urinary concentration of thyroid hormones and 
their carriers has been observed in various kinetic and clinical studies, demonstrating not only a correlation between hypothyroidism and the degree of nephrosis but also a close interconnection with the remission of these conditions. However, several other factors may influence the degree of dysthyroidism in this setting, including thyroid performance and factors influencing hormone biosynthesis, impairment of tubular function and the effect of kidney dysfunction on $\mathrm{T}_{4^{-}}$ $\mathrm{T}_{3}$ peripheral conversion.

\section{WHY SCREENING FOR SUBCLINICAL HYPOTHY- ROIDISM SHOULD BE PERFORMED IN NS}

The role of hypothyroidism in reducing the glomerular filtration rate, changing water homeostasis and, consequently, causing hyponatraemia is well known [30]. It is not uncommon that patients with thyroid hormone deficiency suffer from generalised oedema, primarily due to a reduction in free water clearance [41]. Similarly, oedema, essentially caused by sodium retention and a drop in plasma oncotic pressure, is a common clinical manifestation of NS [42]. Water retention normally worsens renal function in patients with primary glomerulonephritis and patients are usually asked to restrict their dietary fluid and sodium intake and take a diuretic therapy [43]. It is therefore very important to bear in mind that if a nephrotic glomerular disease is accompanied by hypothyroidism, the severe urinary loss of proteins may exacerbate fluid retention, which may be difficult to resolve if the treatment of hypothyroidism is delayed.

Finally, it has been demonstrated that normalising $\mathrm{T}_{3}$ and $\mathrm{T}_{4}$ concentrations with replacement therapy also preserves renal function in patients with a kidney disease and subclinical hypothyroidism, and is an independent predictor of renal outcome [44]. For this reason, even though there are no specific recommendations for thyroid screening in patients with NS, we suggest thyroid function be screened not only in patients with pre-existing thyroid disease but also in those with no history of dysthyroidism. Earlier identification of thyroid hormone abnormalities may improve the global management of nephropathic patients and their comorbidities. In particular, the close relation between hypothyroidism and cardiovascular disease has already been investigated. Thyroid hormones seem to have a direct action on myocardial and vascular function; they can influence endothelial dysfunction, blood pressure control and dyslipidaemia [45, 46]. Furthermore, thyroid deficiency is linked to abnormalities of cardiac myocytes and vascular smooth muscle cells and may interfere with the actions of cardiologic and lipid-lowering therapies [47].

\section{WHEN A SUPPLEMENT THERAPY SHOULD BE CONSIDERED}

The standard treatment for hypothyroidism is $\mathrm{LT}_{4}$, thanks to its great efficacy, simple once-daily oral administration and fast resolution of the signs and symptoms of hypothyroidism in the majority of patients (in 6 weeks at most) [48]. However, the treatment fails to restore thyroid function in a small part (10-15\%) of patients, for whom $\mathrm{LT}_{3}+\mathrm{LT}_{4}$ combination therapy is suggested.

Recent advances in the understanding of thyroid hormone physiology show that genetic variation in deiodinases [49] or in thyroid hormone transporters [50] may be partly responsible for this difference. The clinician's goals must be to resolve hypothyroid signs and symptoms and normalise serum thyroid hormone concentrations $\left(\mathrm{TSH}, \mathrm{FT}_{3}\right.$ and $\mathrm{FT}_{4}$, with $\mathrm{TSH}$ as the marker of replacement treatment adequacy) while avoiding overtreatment (iatrogenic thyrotoxicosis), especially in selected subpopulations (elderly, cardiopathic, etc.). An optimal and consistent absorption is achieved only when $\mathrm{LT}_{4}$ is taken either $60 \mathrm{~min}$ before breakfast or at bedtime ( 3 or more hours after the evening meal) and preferably apart from other potentially interfering medications and supplements [51]. Co-administration with food is likely to impair levothyroxine absorption [52], but it is also important to consider patient adherence: although a fasting regimen may promote absorption, if administration $1 \mathrm{~h}$ before breakfast is unfeasible, $30 \mathrm{~min}$ before breakfast may also be reasonable.

The standard of choice of the minimum effective dose for hypothyroid patients could depend on various different factors, and should ideally be tailored to the patient: actual or ideal body weight, TSH goal, aetiology of hypothyroidism, degree of serum TSH elevation, pregnancy and age. The dose is generally calculated as $1.6-1.8 \mu \mathrm{g} / \mathrm{kg}$ of actual body weight $[48,53,54]$. In some cases, higher doses are required, especially in patients with little residual thyroid function [55]: from $2.0-2.1 \mu \mathrm{g} / \mathrm{kg}$ during primary hypothyroidism, after Basedow ablation or in athyreotic patients [56] to 2.1 $2.7 \mu \mathrm{g} / \mathrm{kg}$ in patients with thyroid cancer [57]. Hypothyroid women taking LT4 typically require a dose increase early in the first trimester of pregnancy [58]. This challenge is required not only because of the well-known requirement for thyroid hormone to develop the fetus' neural tube, but also because of the increased risk of autoimmune kidney disease (e.g. glomerulonephritis) during this period [51].

The replacement $\mathrm{LT}_{4}$ dose required to normalise TSH tends to decrease with age [53]. Experts advise 'starting low and going slow', especially in elderly patients and those with cardiovascular disease, to avoid precipitating cardiac events [59]. Generally, after initiation of the calculated dose, adjustments of 12.5 - $25 \mu \mathrm{g} / \mathrm{day}$ could be made, based on serum TSH. TSH should then be retested at $4-6$ weeks and 4 6 months to enable dose adjustment as necessary, and then monitored yearly [51].

Unfortunately, as yet there are no clinical data on the initiation of replacement therapy with $\mathrm{LT}_{4}$ in patients with NS and subclinical and/or overt hypothyroidism. In fact, although the latest American Thyroid Association guidelines suggest performing thyroid function assessment during NS, they lack any recommendations on dosing, timing and specific adjustments [60].

\section{HOW CAN HYPOTHYROIDISM BE TREATED}

$\mathrm{LT}_{4}$ is generally prescribed worldwide in the form of tablets, although recent data suggest that gelatin capsules or oral liquid formulations may have a more favourable absorption profile in selected circumstances. Due to the lack of randomised controlled trials the use of these different preparations cannot currently be recommended. A switch to a gel capsule or liquid formulation might be worth considering in the rare event of putative allergies to excipients. An alterna- 
tive approach when poor absorption is suspected is to increase the $\mathrm{LT}_{4}$ tablet dose [51].

The gelatin capsule formulation contains liquid $\mathrm{LT}_{4}$ [61] in contrast to standard solid $\mathrm{LT}_{4}$ tablets: this enables fast, efficient dissolution, even at a low $\mathrm{pH}$ [62]. Some studies found that capsules are better absorbed when taken with coffee or proton pump inhibitors [63], allowing suppression of serum TSH in patients who did not reach euthyroidism with standard $\mathrm{LT}_{4}$ tablets [64]. A retrospective uncontrolled trial described lower serum TSH concentrations when switching from tablets to soft gel capsules of the same dose of $\mathrm{LT}_{4}$ [65].

A liquid $\mathrm{LT}_{4}$ formulation has also been proposed. Recent data suggested that this formulation could be better absorbed than tablets in cases of malabsorption (e.g. following bariatric surgery) or in patients taking $\mathrm{LT}_{4}$ during breakfast [66]. Due to its $28 \%$ ethanol content, it is not recommended during pregnancy and breastfeeding or in children and high-risk patients [66]. For patients unable to take oral medications, intravenous administration could be an alternative, with a conversion factor of $75 \%$ with respect to the oral dose. $\mathrm{LT}_{4}$ absorption with food was calculated as $64 \%$ compared with $80 \%$ in the fasting state [52].

The different pharmacological properties are summarised in Table 1. Briefly, although patients with NS show specific thyroid hormone profile changes, to the best of our knowledge no prospective studies have assessed which for-

Table 1. Pharmacological properties of different levothyroxine preparations.

\begin{tabular}{|c|c|c|c|c|c|}
\hline & Half-life (h) & Main Site of Metabolism & Main Contraindications & Possible Advantages & Possible Dosage ( $\mu \mathrm{g})$ \\
\hline Gelatin capsules & $\sim 190$ & $\begin{array}{l}80 \% \text { peripheral deiodination } \\
20 \% \text { hepatic metabolism }\end{array}$ & $\begin{array}{l}\text { Dersensitivity } \\
\text { - Hyperien } \\
\text { - Adrenal insufficiency } \\
\text { - Hypopituitarism } \\
\text { - Thyrotoxicosis }\end{array}$ & $\begin{array}{l}\text { Better absorption } \\
\text { during consumption } \\
\text { with coffee or PPIs }\end{array}$ & $\begin{array}{l}13 \\
25 \\
50 \\
75 \\
88 \\
100 \\
112 \\
125 \\
137 \\
150 \\
175 \\
200\end{array}$ \\
\hline
\end{tabular}


mulation should be preferred to reach euthyroid status as quickly as possible. The only available recommendations originate from a handful of case reports and cannot be considered as reliable.

\section{CONCLUSIONS}

The increased prevalence of hypothyroidism and subclinical hypothyroidism in patients with proteinuria is now well known. However, the pathophysiological mechanisms underlying this condition are not completely understood. It is still unclear if hypothyroidism plays a key role in the course of kidney disease or is an innocent bystander. What does seem to be clear is the worse quality of life and poor prognosis of NS patients with hypothyroidism. Thyroid function in patients with NS should thus be assessed as soon as possible, in order to treat this potential complication. Euthyroidism can now be restored by simple and versatile pharmacological treatment, tailored to the patient. Further studies are needed to establish the prevalence and diagnostic challenges of hypothyroidism in the course of NS, to find reliable new thyroid function biomarkers in kidney proteinuric disease and to establish the best replacement therapy.

\section{LIST OF ABBREVIATIONS}

$\begin{array}{lll}\mathrm{DIT} & = & \text { Di-iodinated tyrosine } \\ \mathrm{FT}_{3} & = & \text { Free } \mathrm{T}_{3} \\ \mathrm{FT}_{4} & = & \text { Free } \mathrm{T}_{4} \\ \mathrm{LT}_{4} & = & \text { Levothyroxine } \\ \mathrm{MIT} & = & \text { Mono-iodinated tyrosine } \\ \mathrm{NS} & = & \text { Nephrotic syndrome } \\ \mathrm{T}_{3} & = & \text { Tri-iodothyronine } \\ \mathrm{T}_{4} & = & \text { Thyroxine } \\ \mathrm{TBG} & = & \text { Thyroxine-binding globulin } \\ \mathrm{TSH} & = & \text { Thyroid-stimulating hormone }\end{array}$

\section{CONFLICT OF INTEREST}

There are no known conflicts of interest associated with this publication and there has been no financial support for this work.

\section{ACKNOWLEDGEMENTS}

Declared none.

\section{REFERENCES}

[1] Gilles R, den Heijer M, Ross AH, et al. Thyroid function in patients with proteinuria. Neth J Med. 2008; 66: 483-485.

[2] Kidney Disease: Improving Global Outcomes (KDIGO) Glomerulonephritis Work Group. KDIGO Clinical Practice Guideline for Glomerulonephritis. Kidney Inter Suppl. 2012; 2:139-274.

[3] Garber JR, Cobin RH, Gharib H, et al. American Association Of Clinical Endocrinologists And American Thyroid Association Taskforce On Hypothyroidism In Adults. Clinical practice guidelines for hypothyroidism in adults: cosponsored by the American Association of Clinical Endocrinologists and the American Thyroid Association. Thyroid. 2012; 22:1200-1235.
Mondal S, Raja K, Schweizer U, et al. Chemistry and Biology in the Biosynthesis and Action of Thyroid Hormones. Angew Chem Int Ed Engl. 2016; 55: 7606-7630.

[5] Melmed S, Williams Textbook of Endocrinology, $13^{\text {th }}$ ed. Elsevier. pp. 18-22.

[6] Pilo A, Iervasi G, Vitek F, et al. Thyroidal and peripheral production of 3,5,3ф-triiodothyronine in humans by multicompartmental analysis. Am J Physiol. 1990;258: E715-E726.

[7] Schussler GC. The thyroxine-binding proteins. Thyroid. 2000;10:141-149.

[8] Wu SY, Green WL, Huang WS, et al. Alternate pathways of thyroid hormone metabolism. Thyroid. 2005;15:943-958.

[9] Evans RM. The steroid and thyroid hormone receptor superfamily. Science. 1988;240: 889-895.

[10] Cooper DS. Subclinical hypothyroidism. N Engl J Med. 2001;345:260-265

[11] McQuade C, Skugor M, Brennan DM, et al. Hypothyroidism and moderate subclinical hypothyroidism are associated with increased all-cause mortality independent of coronary heart disease risk factors: a PreCIS database study. Thyroid. 2011; 21: 837-843.

[12] Rodondi N, Bauer DC, Cappola AR, et al. Subclinical thyroid dysfunction, cardiac function, and the risk of heart failure. The Cardiovascular Health study. J Am Coll Cardiol. 2008; 52:11521159.

[13] Hull RP, Goldsmith DJ. Nephrotic syndrome in adults. BMJ. 2008; 336(7654):1185-1189.

[14] Malafronte P, Mastroianni-Kirsztajn G, Betônico GN, et al. Paulista Registry of glomerulonephritis: 5-year data report. Nephrol Dial Transplant. 2006; 21:3098.

[15] Rivera F, López-Gómez JM, Pérez-García R. Spanish Registry of Glomerulonephritis. Clinicopathologic correlations of renal pathology in Spain. Kidney Int. 2004; 66:898.

[16] Gesualdo L, Di Palma AM, Morrone LF, et al. The Italian experience of the national registry of renal biopsies. Kidney Int. 2004; 66:890.

[17] Pofi R, Di Mario F, Gigante A, et al. Diabetic Nephropathy: Focus on Current and Future Therapeutic Strategies. Curr Drug Metab. 2016;17:497-502.

[18] Park SJ, Shin JI. Complications of nephrotic syndrome. Korean J Pediatr. 2011; 54:322-328.

[19] Davison AM. Oxford textbook of clinical nephrology. $3^{\text {rd }}$ ed. New York: Oxford University. pp 421.

[20] Epstein AA. Thyroid therapy and thyroid tolerance in chronic nephrosis. JAMA. 1926; 87: 913.

[21] Recant L, Riggs DS. Thyroid function in nephrosis. J Clin Invest. 1952; 31:789.

[22] Afrasiabi MA, Vaziri D, Gwinup G, et al. Thyroid function studies in the nephrotic syndrome. Ann Intern Med. 1979; 90: 335-338.

[23] Gavin LA, McMahon FA, Castle JN, et al. Alteration in serum thyroid hormones and thyroxine-binding globulin in patients with nephrosis. JCEM. 1978; 46: 125-130.

[24] Fonseca V, Thomas M, Katrak A, et al. Can urinary thyroid hormone loss cause hypothyroidism? Lancet. 1991; 338: 475-476.

[25] Faber J, Siersbaek-Nielsen K, Kirkegaard C. Renal handling of thyroxine, 3,5,3'- and 3,3',5'-triiodothyronine, 3,3'- and 3',5'diiodothyronine in man. Acta Endocrinol (Copenh). 1987;115:144148.

[26] Faber J, Busch-Sorensen M, Rogowski P, et al. Urinary excretion of free and conjugated 3',5'-diiodothyronine and 3,3'diiodothyronine. J Clin Endocrinol Metab. 1981; 53: 587-593.

[27] Burke CW, Shakespear RA. Triiodothyronine and thyroxine in urine. II. Renal handling, and effect of urinary protein. J Clin Endocrinol Metab. 1976; 42: 504-513.

[28] Afroz S, Khan AH, Roy DK. Thyroid function in children with nephrotic syndrome. Mymensingh Med J. 2011; 20: 407-411.

[29] Chadha V, Alon US. Bilateral nephrectomy reverses hypothyroidism in congenital nephrotic syndrome. Pediatr Nephrol. 1999; 13:209-211.

[30] Iglesias P, Díez JJ. Thyroid dysfunction and kidney disease. Eur J Endocrinol. 2009; 160: 503-515.

[31] Junglee NA, Scanlon MF, Rees DA. Increasing thyroxine requirements in primary hypothyroidism: don't forget the urinalysis. J Postgrad Med. 2006; 52: 201-203.

[32] Feinstein EI, Kaptein EM, Nicoloff JT, et al. Thyroid function in patients with nephrotic syndrome and normal renal function. Am J Nephrol. 1982; 2: 70-76. 
[33] Yoshida K1, Sakurada T, Kaise K, et al. Measurement of thyroid stimulating hormone (TSH) in human urine. Endocrinol Jpn. 1988; 35: 733-739.

[34] Dagan A, Cleper R, Krause I. Hypothyroidism in children with steroid-resistant nephrotic syndrome. Nephrol Dial Transplant. 2012; 27: 2171-2175.

[35] Verhelst J, Berwaerts J, Marescau B, et al. Serum creatine, creatinine, and other guanidine compounds in patients with thyroid dysfunction. Metabolism. 1997; 46: 1063-1067.

[36] Vargas F, Moreno JM, Rodriguez Gomez I, et al. Vascular and renal function in experimental thyroid disorders. Eur J Endocrinol. 2006; 154: 197-212.

[37] Nikolaeva AV, Pimenov LT. Lipid metabolism and functional status of the kidney in hypothyroid patients depending on the phase of disease. Terapevticheskii Arkhiv. 2002; 74: 20-23.

[38] Adlkofer F, Hain H, Meinhold H, et al. Thyroid function in patients with proteinuria and normal or increased serum creatinine concentration. Acta Endocrinol (Copenh). 1983; 102: 367-376

[39] El Ters M, Patel SM, Norby SM. Hypothyroidism and reversible kidney dysfunction: an essential relationship to recognize. Endocr Pract. 2014; 20:490-499.

[40] Peters JP, Man EB. The relation of albumin to precipitable iodine of serum. J Clin Invest. 1948; 27: 397.

[41] Schrier RW. Body water homeostasis: clinical disorders of urinary dilution and concentration. J Am Soc Nephrol. 2006; 17:18201832.

[42] Perico N, Remuzzi G. Edema of the nephrotic syndrome: the role of the atrial peptide system. Am J Kidney Dis. 1993; 22: 355-366.

[43] Qavi AH, Kamal R, Schrier RW. Clinical Use of Diuretics in Heart Failure, Cirrhosis, and Nephrotic Syndrome. Int J Nephrol. 2015; 2015: 975934

[44] Shin DH, Lee MJ, Seung JK. Preservation of renal function by thyroid hormone replacement therapy in chronic kidney disease patients with subclinical hypothyroidism. J Clin Endocrinol Metab. 2012; 97:2732-2740.

[45] Jabbar A, Pingitore A, Pearce SH, et al. Thyroid hormones and cardiovascular disease. Nat Rev Cardiol. 2017; 39-55.

[46] Klein I, Danzi S. Thyroid Disease and the Heart. Curr Probl Cardiol. 2016; 65-92.

[47] Lioudaki E, Mavroeidi NG, Mikhailidis DP, et al. Subclinical hypothyroidism and vascular risk: an update. Hormones (Athens). 2013; 12(4):495-506.

[48] Fish LH, Schwartz HL, Cavanaugh J, et al. Replacement dose, metabolism and bioavailability of levothyroxine in the treatment of hypothyroidism. Role of triiodothyronine in pituitary feedback in humans. N Engl J Med. 1987; 316:764-770.

[49] Tonacchera M, De Marco G, Agretti P, et al. Identification and functional studies of two new dual-oxidase 2 (DUOX2) mutations in a child with congenital hypothyroidism and a eutopic normalsize thyroid gland. J Clin Endocrinol Metab. 2009; 94: 4309-4314.

[50] Wiersinga WM, Duntas L, Fadeyev V, et al. ETA Guidelines: The Use of L-T4 + L-T3 in the Treatment of Hypothyroidism. Eur Thyroid J. 2012;1: 55-71.

[51] Jonklaas J, Bianco AC, Bauer AJ, et al. American Thyroid Association Task Force on Thyroid Hormone Replacement. Guidelines for the treatment of hypothyroidism: prepared by the American thyroid association task force on thyroid hormone replacement. Thyroid. 2014; 24:1670-1751.

[52] Wenzel KW, Kirschsieper HE Aspects of the absorption of oral Lthyroxine in normal man. Metabolism. 1977; 26:1-8.

[53] Jonklaas J. Sex and age differences in levothyroxine dosage requirement. Endocr Pract. 2010; 16: 71-79.

[54] Roos A, Linn-Rasker SP, van Domburg RT, et al. The starting dose of levothyroxine in primary hypothyroidism treatment: a prospective, randomized, double-blind trial. Arch Intern Med. 2005; 165: 1714-1720.

[55] Loh JA, Wartofsky L, Jonklaas J, et al. The magnitude of increased levothyroxine requirements in hypothyroid pregnant women depends upon the etiology of the hypothyroidism. Thyroid. 2009; 19:269-75

[56] Gordon MB, Gordon MS. Variations in adequate levothyroxine replacement therapy in patients with different causes of hypothyroidism. Endocr Pract. 1999; 5:233-238.

[57] Burmeister LA, Goumaz MO, Mariash CN, et al. Levothyroxine dose requirements for thyrotropin suppression in the treatment of differentiated thyroid cancer. J Clin Endocrinol Metab. 1992; 75:344-350.

[58] Alexander EK, Marqusee E, Lawrence J, et al. Timing and magnitude of increases in levothyroxine requirements during pregnancy in women with hypothyroidism. N Engl J Med. 2004; 351:241-249.

[59] Wartofsky L. Levothyroxine therapy for hypothyroidism: should we abandon conservative dosage titration? Arch Intern Med 2005;165:1683-1684.

[60] Chandurkar V, Shik J, Randell E. Exacerbation of underlying hypothyroidism caused by proteinuria and induction of urinary thyroxine loss: case report and subsequent investigation. Endocr Pract. 2008; 14:97-103.

[61] Benvenga S. (Soft) capsules of wisdom: preventing myoinositol malabsorption caused by coffee. Expert Opin Drug Deliv. 2012; 9:1177-1179.

[62] Colucci P, D'Angelo P, Mautone G et al. Pharmacokinetic equivalence of a levothyroxine sodium soft capsule manufactured using the new food and drug administration potency guidelines in healthy volunteers under fasting conditions. Ther Drug Monit. 2011; 33:355-361.

[63] Vita R, Benvenga S. Tablet levothyroxine (L-T4) malabsorption induced by proton pump inhibitor; a problem that was solved by switching to L-T4 in soft gel capsule. Endocr Pract. 2014; 20:e38e41.

[64] Vita R, Saraceno G, Trimarchi F, et al. A novel formulation of Lthyroxine (L-T4) reduces the problem of L-T4 malabsorption by coffee observed with traditional tablet formulations. Endocrine. 2014; 43:154-160.

[65] Brancato D, Scorsone A, Saura G, et al. Comparison of TSH Levels with liquid formulation versus tablet formulations of levothyroxine in the treatment of adult hypothyroidism. Endocr Pract. 2014; 20:657-662.

[66] Cappelli C, Pirola I, Gandossi E, et al. Oral liquid levothyroxine treatment at breakfast: a mistake? Eur J Endocrinol. 2014; 170:9599. 